\title{
Neonatal Jaundice
}

\author{
Yousif M Elhaj ${ }^{1 *}$, Mosab Nouraldein Mohammed Hamad ${ }^{2}$ \\ ${ }^{1}$ Faculty of Medicine, Karary University, Sudan \\ ${ }^{2}$ Medical Laboratory Science Department, Faculty of Health Science, Elsheikh Abdallah Elbadri University, Sudan
}

\author{
DOI: $10.36348 /$ sjbr.2020.v05i03.003
}

| Received: 23.02.2020 | Accepted: 01.03.2020 | Published: 08.03.2020

*Corresponding author: Yousif M Elhaj

\section{Abstract}

This review article discussed on neonatal jaundice which is a yellowish discoloration of the white part of the eyes and skin in a newborn baby due to high bilirubin levels Other clinical features may include excess sleepiness or loss of appetite. Consequences may include seizures, cerebral palsy. It may happen due to physiologic or pathologic etiologies. The need for treatment relies on bilirubin levels, the age of the child, and the underlying cause treatment may include more frequent feeding, phototherapy, or exchange transfusions.

Keywords: Neonatal jaundice, bilirubin, liver, conjugation.

Copyright @ 2020: This is an open-access article distributed under the terms of the Creative Commons Attribution license which permits unrestricted use, distribution, and reproduction in any medium for non-commercial use (NonCommercial, or CC-BY-NC) provided the original author and source are credited.

\section{BACKGROUND}

Neonatal jaundice may have first been described in a Chinese textbook 1000 years ago [1]. It is frequently an ordinary physiologic state happening throughout the transitional period after birth. It is not a singular illness in itself, but a physical result connected with several possible reasons. Harsh neonatal jaundice is measured to be pathophysiologic. Jaundice reflects the gathering of the yellow-orange pigment bilirubin in the skin, sclerae, and other tissues; it does not entail any particular causation [2]. Neonatal jaundice is a widespread state global happening in up to $60 \%$ of term and $80 \%$ of preterm newborns in the first week of life. Although severe hyperbilirubinaemia is uncommon in urbanized countries it is still fairly common in developing countries often resulting in kernicterus with its assistant medical, economic and social load on the patient, family and society in general [3].

With such diverse definitions of neonatal jaundice and hyperbilirubinaemia, it is hard to evaluate the scale of the trouble in neonatal units from dissimilar regions or areas. In the United States, the National Collaborative Perinatal Project revealed that $6.2 \%$ of infants weighing more than $2500 \mathrm{~g}$ had serum bilirubin concentrations exceeding 220 umol/l (12.9 mgldl). Data derived from 12587 babies (2500g or more), born in Singapore from 1986 to 1989 [4], showed a frequency of this degree of neonatal jaundice of only $4.6 \%$; Asian full-term babies are smaller in size but, if normal birth weight is defined as more than $2270 \mathrm{~g}$, still only $5.2 \%$ had bilirubin concentrations in this range. We assume that since we have been able to treat our babies' early subsequent attainment of more phototherapy units and the adoption of a more open-minded policy to institute treatment for milder jaundiced infants, we have reduced the incidence of severe jaundice [4].

The most frequent reason of jaundice in bilirubin within the first 24 hours of life should be first 24 hours of life due to HDN is rhesus ( $\mathrm{Rh}$ ) hemolytic sickness. As the mother becomes sensitized due to fetomaternal transfusions in preceding pregnancies, anti-D IgM and IgG are formed. Anti-D IgG is responsible for rhesus illness in the neonate as this antibody can cross placenta. Rhesus ( $\mathrm{Rh}$ ) incongruity develops between an Rh-negative mother (previously sensitized) and her Rh-positive fetus [5]. Many workers have suggested lately that the incidence of substantial neonatal jaundice has amplified. Alterations in obstetric perform have been responsible for this raise, chiefly the amplified employ of oxytocin for inducing labour. But this amplified incidence of neonatal jaundice is mostly based on clinical feeling, and the function of oxytocin in producing the augment is hard to confirm since oxytocin use is connected with other icterogenic factors such as preterm delivery, instrumental delivery, and epidural anesthesia [6].

The device of this bilirubinemia is multifactorial, as lately summarized, and comprises mainly processes participating to amplified bilirubin load, or decreased bilirubin clearance. The previous 
may be the consequence of factors that enhance bilirubin production and the enterohepatic circulation, while the second is principally the result of immature conjugative capacity, even though impaired hepatic uptake or emission may also play a part. It has been recommended that serum total bilirubin (STB) concentrations that stay within the physiologic range result from balance between bilirubin production and removal. In contrast, in some neonates, inequity between these mechanisms may happen, with bilirubin creation being comparatively higher than conjugation. This disparity is thought to result in hyperbilirubinemia [7].

\section{THERAPEUTIC METHODS}

While the majority of newborns with jaundice are otherwise healthy, they need to be monitored because bilirubin is potentially poisonous to the central nervous system. Adequately elevated levels of bilirubin can guide to bilirubin encephalopathy and then kernicterus, with overwhelming, permanent neurodevelopmental handicaps. The purpose of treatment is to decrease the concentration of circulating bilirubin or maintain it from increasing. Phototherapy attains this by using light energy to alter the shape and structure of bilirubin, changing it to molecules that can be excreted even when normal conjugation is poor. Absorption of light by dermal and subcutaneous bilirubin causes a fraction of the pigment to experience a number of photochemical reactions that happen at very dissimilar rates. These reactions produce yellow stereoisomers of bilirubin and colorless derivatives of lower molecular weight. The outcomes are less lipophilic than bilirubin, and dissimilar bilirubin, they can be excreted in bile or urine with no need for conjugation [8].

\section{REFERENCES}

1. Thor WR Hansen. Neonatal Jaundice. https:/emedicine. medscape. com/ article/ 974786-overview.

2. Cohen, R. S., Wong, R. J., \& Stevenson, D. K. (2010). Understanding neonatal jaundice: a perspective on causation. Pediatrics \& Neonatology, 51(3), 143-148.

3. Onyearugha, C. N., Onyire, B. N., \& Ugboma, H. A. A. (2013). Neonatal jaundice: Prevalence and associated factors as seen in Federal Medical Centre Abakaliki, Southeast Nigeria. International Journal of Paediatrics and Child Health, 1(2):1620.

4. Ho, N. K. (1992). Neonatal jaundice in Asia. Baillière's clinical haematology, 5(1), 131142.

5. Irshad, M., Mohammad, A., Hussain, M., Khan, B., Ali, N., Ahmad, A., ... \& Karim, R. (2011). Prevalence of Rhesus type and ABO incompatibility in jaundiced neonates. JPMI, 25(03), 233-239.

6. Friedman, L., Lewis, P. J., Clifton, P., \& Bulpitt, C. J. (1978). Factors influencing the incidence of neonatal jaundice. Br Med J, 1(6122), 1235-1237.

7. Kaplan, M., Muraca, M., Hammerman, C., Rubaltelli, F. F., Vilei, M. T., Vreman, H. J., \& Stevenson, D. K. (2002). Imbalance between production and conjugation of bilirubin: a fundamental concept in the mechanism of neonatal jaundice. Pediatrics, 110(4), e47-e47.

8. Maisels, M. J., \& McDonagh, A. F. (2008). Phototherapy for neonatal jaundice. New England Journal of Medicine, 358(9), 920-928. 